\title{
Kunstausstellung der Schweizer Ärzte - Salon des médecins suisses
}

\section{Künzler}

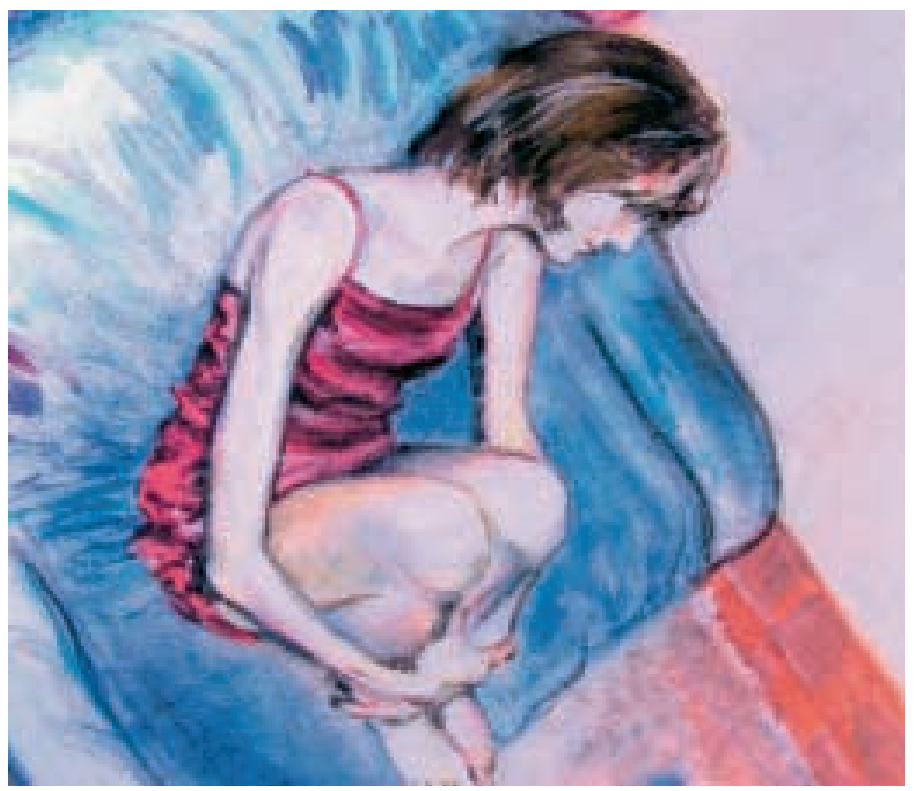

Susanne Dennler: «Julia».

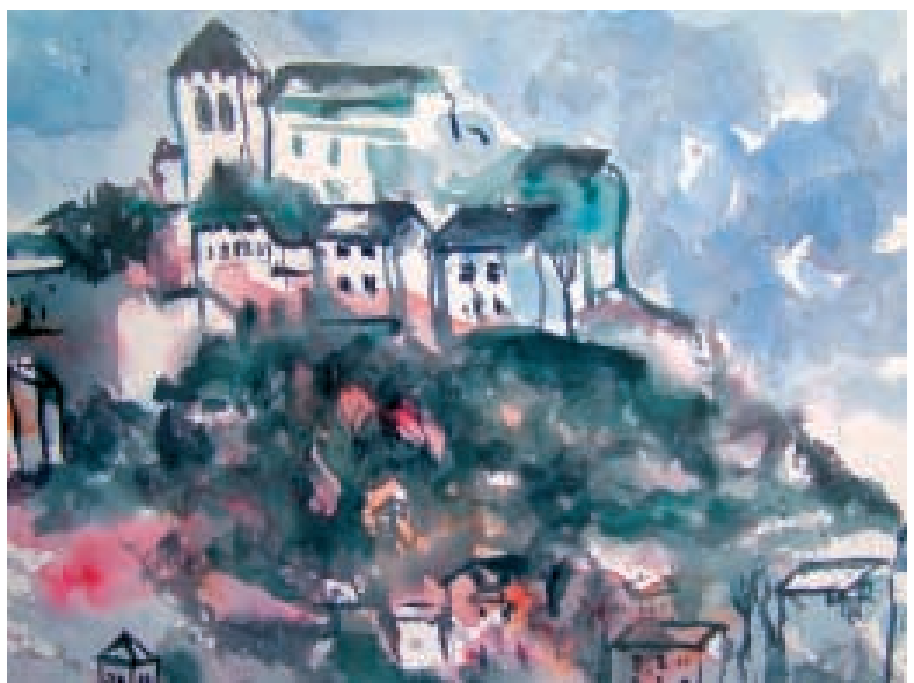

Severin Weiss ( $\dagger$ ): Sion I, Aquarell.

Korrespondenz:

Dr. med. David Künzler

Jakob Zürrer-Strasse 35

CH-8915 Hausen am Albis
Die Medizin ist eine Kunst. Und sie ist traditionellerweise eng mit anderen Künsten wie Malerei, Bildhauerei und Musik verknüpft. Viele Ärztinnen und Ärzte finden im künstlerischen Schaffen einen Ausgleich zum Berufsalltag, aber die wenigsten von ihnen haben eine Gelegenheit, ihre Werke einer breiteren Öffentlichkeit zugänglich zu machen. Deshalb wurde bereits vor mehr als 50 Jahren der Verein «Kunstausstellung der Schweizer Ärzte» gegründet, welcher Ausstellungen mit Werken seiner zurzeit fast 100 Mitglieder organisiert. Seit mehreren Jahren findet jeweils gegen den Herbst zu eine solche Ausstellung im Rathauskeller in Murten statt. Bewusst wird dabei auf den Verkauf der Exponate verzichtet. (Die Vereinsmitgliedschaft steht allen malenden, fotografierenden oder plastisch gestaltenden Medizinstudentinnen und -studenten, Ärztinnen und Ärzten sowie deren Gattinnen und Gatten offen.)

Auch 2004 fand vom 14. bis 28. August die Ausstellung statt und zeigte eine grosse Vielfalt von Stilen und Ausdrucksmöglichkeiten. Wie

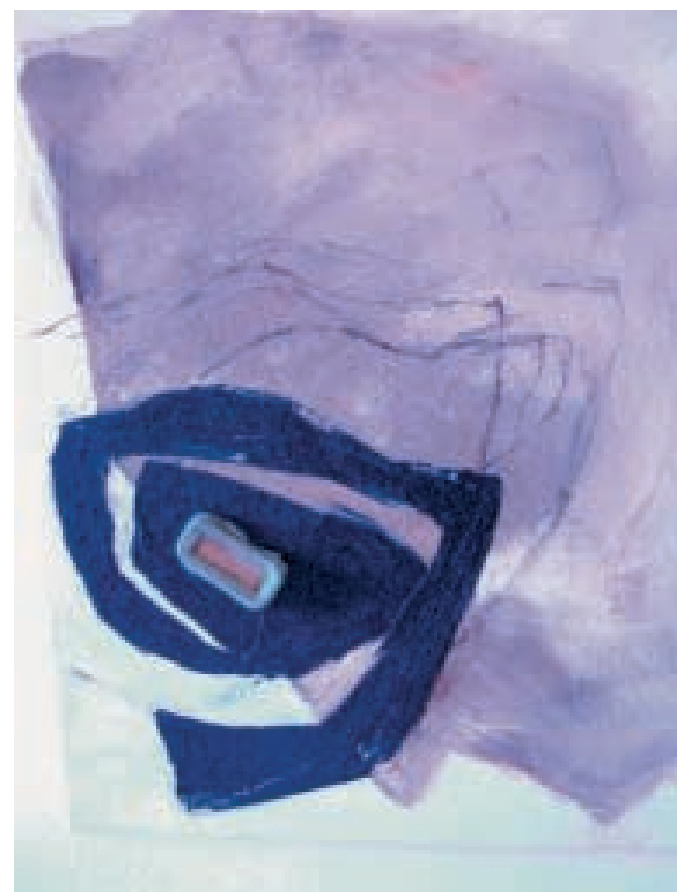

Masé Jardenah: «Augenblick». 


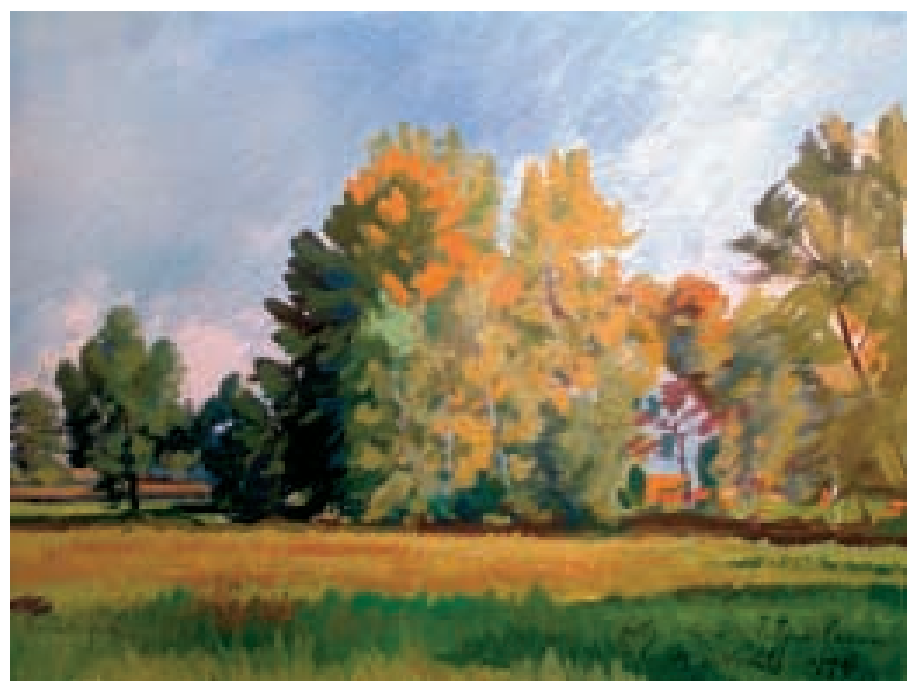

immer wurde die Vernissage eingeleitet mit einem Konzert in der französischen Kirche, wo Dr. med. J.-L. Darbellay mit Mitgliedern seiner Familie klassische und moderne Werke zur Aufführung brachte und Vertonungen von Gedichten von Mitgliedern der ASEM (Vereinigung der Schweizer Schriftstellerärzte) zu hören waren.

Nachfolgend sehen Sie eine kleine Auswahl der anlässlich der letzten Ausstellung gezeigten Bilder.

Die nächste Ausstellung in Murten findet vom 20. August bis 3. September 2005 statt.

Mehr über die Vereinigung, weitere Ausstellungen, Beitritt usw. finden Sie auf unserer Homepage www.aerzte-kunst.ch.

Willy Felgenhauer: «Diepoldsau», Gouache.

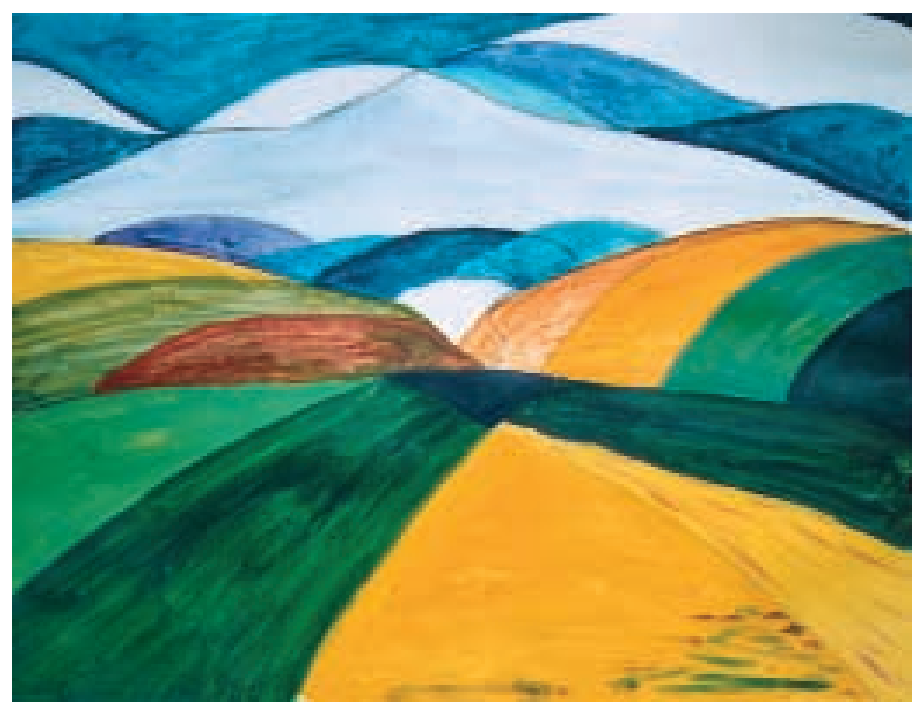

David Künzler: «Rigi Il», Acryl.

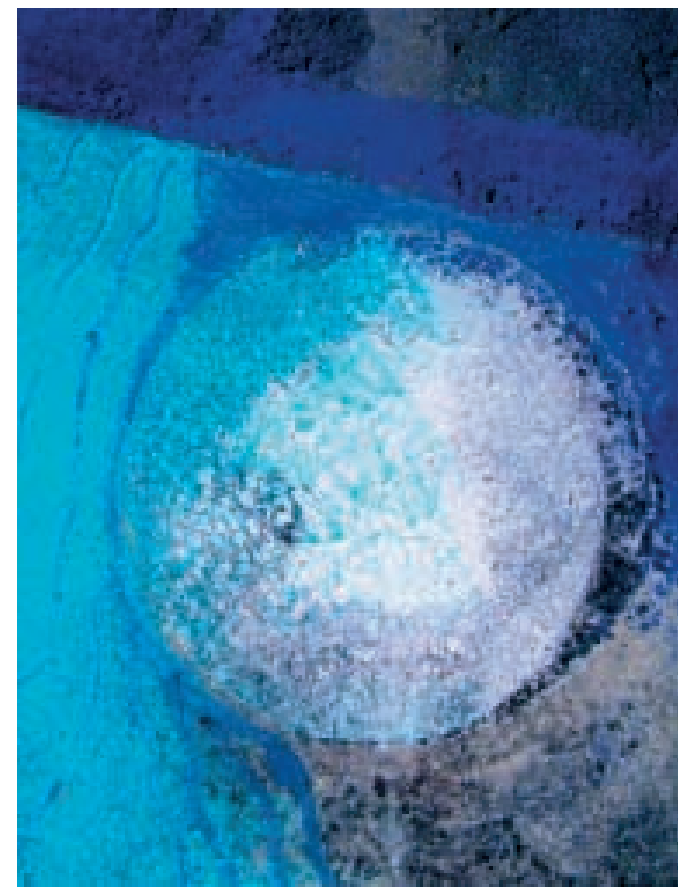

Marianne Ramser: «Unsere kleine Welt». 